\title{
The Changing Face of Mastectomy (from Mutilation to Aid to Breast Reconstruction)
}

\author{
Stefano Zurrida, ${ }^{1,2}$ Fabio Bassi, ${ }^{1}$ Paolo Arnone, ${ }^{1}$ Stefano Martella, ${ }^{3}$ Andres Del Castillo, ${ }^{1}$ \\ Rafael Ribeiro Martini, ${ }^{1}$ M. Eugenia Semenkiw, ${ }^{1}$ and Pietro Caldarella ${ }^{1}$ \\ ${ }^{1}$ Division of Senology, European Institute of Oncology, 20141 Milan, Italy \\ ${ }^{2}$ School of Medicine, University of Milan, 20141 Milan, Italy \\ ${ }^{3}$ Division of Plastic Surgery, European Institute of Oncology, 20141 Milan, Italy
}

Correspondence should be addressed to Stefano Zurrida, stefano.zurrida@ieo.it

Received 22 December 2010; Accepted 10 February 2011

Academic Editor: Anees B. Chagpar

Copyright (C) 2011 Stefano Zurrida et al. This is an open access article distributed under the Creative Commons Attribution License, which permits unrestricted use, distribution, and reproduction in any medium, provided the original work is properly cited.

\begin{abstract}
Breast cancer is the most common cancer in women. Primary treatment is surgery, with mastectomy as the main treatment for most of the twentieth century. However, over that time, the extent of the procedure varied, and less extensive mastectomies are employed today compared to those used in the past, as excessively mutilating procedures did not improve survival. Today, many women receive breast-conserving surgery, usually with radiotherapy to the residual breast, instead of mastectomy, as it has been shown to be as effective as mastectomy in early disease. The relatively new skin-sparing mastectomy, often with immediate breast reconstruction, improves aesthetic outcomes and is oncologically safe. Nipple-sparing mastectomy is newer and used increasingly, with better acceptance by patients, and again appears to be oncologically safe. Breast reconstruction is an important adjunct to mastectomy, as it has a positive psychological impact on the patient, contributing to improved quality of life.
\end{abstract}

\section{Introduction}

Escharotic materials and cautery were the main treatments for breast cancer for hundreds years. Various simple mastectomy procedures were introduced during the nineteenth century, but none was able to cure the disease or achieve adequate disease control [1].

\section{Radical Mastectomy}

The modern era of surgical treatment for primary breast cancer began in the 1890s with the introduction of radical mastectomy by Halsted and Meyer. William Stewart Halsted reported his work briefly in 1890 and published his more extensive experience of patients treated at Johns Hopkins Hospital, Baltimore, in November 1894 [2]. Willy Meyer published his experience of New York patients in December 1894 [3]. Some of Halsted and Meyer's patients were cured of their disease, so for the first time, physicians had an effective treatment for breast cancer, and radical mastectomy quickly became the standard of care for the disease.

2.1. The Halsted-Meyer Theory. Radical mastectomy was based on the idea that at first, breast cancer spread only locally or "centrifugally" by first invading contiguous tissue and then spreading though lymph ducts to close-by lymph nodes, where the cells were "trapped" for some time. Haematic spread of tumour cells-giving rise to distant metastases - was considered to occur at a later stage.

2.2. Features of Radical Mastectomy. Radical mastectomy involves the removal of all breast tissue, overlying skin, and both pectoralis muscles, together with complete en bloc removal of the axillary lymph nodes. Skin was removed because the disease often involved the skin; in fact, the skin was often ulcerated on presentation $[2,4]$. The pectoralis muscles were removed not simply because the chest wall was often involved, but because it was considered essential 
to remove the transpectoral lymphatic pathways that run directly through the pectoralis major to Rotter's nodes between the pectoralis major and pectoralis minor. At that time, it was also considered anatomically impossible to do a complete axillary dissection without removing the pectoralis muscles [2, 3].

Halsted achieved a three-year local recurrence rate of $3 \%$ and locoregional recurrence rate of $20 \%$ with no perioperative mortality. Five-year survival was $40 \%$-twice that of untreated patients [2]. However, morbidity after the operation was great, because the large wounds were left to heal by granulation, lymphedema was near universal, and arm movement was severely restricted (due to pectoralis muscle removal and damage to axilla nerves). For these reasons, chronic pain was also an important sequela. Over a century ago, surgeons were faced with large breast cancers that seemed to require drastic treatment to have some chance of cure: patients' quality of life was not a consideration [4$10]$.

Nevertheless, thanks to Halsted and Meyer, at last, it became possible to cure breast cancer in some cases, and systematic knowledge of the disease began to accumulate, standardized treatments started being applied, and controlled long-term studies would eventually be conducted. It also became apparent that some women with advanced disease did not benefit from surgical treatment, and as the twentieth century advanced, the concepts of operability and inoperability were developed, largely by Haagensen and Stout [11].

From 1930 onward, orthovoltage radiotherapy was added to mastectomy in many treatment centers although the radiation dose and size and location of treatment fields varied considerably [12-14].

2.3. Extended Radical Mastectomies. According to the Halsted-Meyer theory the most important pathway for breast cancer dissemination was through the lymphatic ducts. The implication was that chances of cure were increased by performing wider (and ever more mutilating) surgical resections that removed more lymph nodes [15]. From 1920 onwards, Samson Handley employed an "extended" radical mastectomy that included removal of the lymph nodes of the internal mammary chain. He also implanted radium needles into the anterior intercostal spaces in order to treat internal mammary nodes. Richard Handley, Samson Handley's son, studied internal mammary chain nodal involvement in breast cancer, demonstrating that $33 \%$ of 150 breast cancer patients had internal mammary chain involvement at the time of surgery [16]. Andbeassen et al. [17] in Denmark and Margottini [18] in Italy performed extrapleural dissection of the internal mammary nodes [19], while Wangensteen [20] in the USA performed supraclavicular and internal mammary node dissection through a sternal approach. Urban [21], at the Memorial Sloan-Kettering Hospital of New York, performed a massive 4-5 hour operation that combined radical mastectomy with resection of the internal mammary chain en bloc with costal cartilages and intercostal muscles; defects were made good with a fascia lata graft.

\section{Reduced Mastectomies}

3.1. The Patey-Dyson Mastectomy. The centrifugal spread idea held sway throughout the first half of the 20th century, and progress in breast cancer treatment was considered, at least by some [22], to depend on even more radical ablations. But perhaps the first indication that extended radical mastectomies were not necessary came from a study by Gray [23] published in 1940, which showed that the dermis was rich in lymphatic vessels and likely to be a plane of ready cancer spread, while the fascia underlying the breast was practically devoid of lymphatic vessels, which for this reason was unlikely to be a major plane of cancer spread. These findings encouraged some surgeons to remove more skin; however, Patey and Dyson [24] experimented with a reduced mastectomy that preserved the pectoralis major: in their 1948 paper, they reviewed mastectomies performed between 1930 and 1943, comparing their operation (which spared the pectoralis major) with the standard radical mastectomy. They found no difference in survival or local recurrence rates between the two groups. Patey wrote "Until an efficient general agent for the treatment of carcinoma of the breast is developed, a high proportion of cases are doomed to die of the disease whatever combination of local treatment by surgery and irradiation is used, because in such a high proportion of cases the disease has passed outside the field of local attack when the patient first comes for treatment."

3.2. The Madden-Auchincloss Mastectomy. In 1972, Madden and colleagues [25] presented results of a consecutive series of patients treated by their "modified" radical mastectomy, in which both the pectoralis major and the pectoralis minor were preserved. Outcomes were similar to those using the radical mastectomy. Patey argued that complete axillary dissection was not possible if the pectoralis minor was preserved. It was also argued that the pectoralis minor's nerve and blood supply were not conserved, leaving the muscle useless [24].

However, Madden's lymphangiographic data showed it was possible to clear the axilla. It was also possible to preserve the neurovascular supply to the pectoralis minor muscle [25]. Auchincloss [26] also presented data in favour of the modified radical mastectomy that conserved the pectoralis minor. Auchincloss also questioned the need to perform complete axillary dissection, suggesting that the apical nodes (Berg level III-[27]) should only be removed when evidently invaded.

Crile [28] went further and suggested that axillary dissection should not be performed immediately if the axilla was not evidently involved, at least in patients with stage I breast cancer, but only subsequently if axillary involvement developed. Survival rates following delayed axillary dissection were equal to or better than following prophylactic lymph node dissection [28].

Another objection to preservation of the pectoralis minor was that the interpectoral lymphatic (Rotter) nodes could be a source of disease recurrence. However, recurrence at 
this site is unusual, and even if it occurs, muscle invasion is uncommon.

3.3. Simple Mastectomy. The simple mastectomy was first developed by Kennedy and Miller [29], based on indications that radical mastectomy was not always necessary in women with breast cancer. Simple mastectomy is a fairly rapid operation in which the pectoral fascia is removed in bloc with the breast, but neither the pectoralis muscles nor the axillary lymph nodes are removed. Kaae and Johansen [30] compared simple mastectomy plus postoperative radiotherapy with extended radical mastectomy plus radiotherapy and found that overall survival rates were similar in both.

\section{Breast Conservation as an Alternative to Mastectomy}

The controversy between extended and reduced mastectomies crystallized in the 1970s when Bernard Fisher marshalled evidence that breast cancer was a systemic disease from the outset and that distant metastases were present well before diagnosis in most cases. The implication was that extended mastectomies were useless. However, Fisher also cited evidence that debulking the tumor mass might stimulate the body to destroy remnant tumor cells by immunologic and other mechanisms, perhaps in combination with systemic cytotoxic agents [31]. These ideas stimulated surgeons to experiment with breast-conserving treatments for breast cancer, variably combined with elective axillary dissection, radiotherapy to the residual breast, and chemotherapy. The first major clinical trials investigating breast conservation began in the 1970s, in coincidence with more widespread use of mammography to identify small lesions and permit diagnosis of breast cancer at an earlier stage. The first to trial to publish five-year results was that of Veronesi's group in Milan [32]. This trial compared quadrantectomy plus radiotherapy plus axillary dissection with radical mastectomy and found no difference between the two treatments. Subsequently, Fisher et al. [33] published five-year results of their trial comparing lumpectomy with "total mastectomy" that removed the entire breast, pectoral fascia, and axillary contents en bloc. Twenty-year followup of both these landmark studies [34, 35] confirmed that conservative breast surgery is equivalent to mastectomy as a treatment for breast cancer. This was an important advance, as the mutilation that went with mastectomy was considerably reduced by the conservative approach.

\section{New Mastectomies}

Today the standard of care for patients with stage I/II breast cancer is lumpectomy or a more extended resection like quadrantectomy, followed by whole breast irradiation [3436]. However, for more advanced disease, and a number of other indications, such as inflammatory breast cancer, intraepithelial neoplasia not amenable to breast-conserving surgery, or local recurrence after breast conserving surgery, mastectomy is necessary. At the same time, the mastectomy operation continues to undergo modification as part of the shift to less extensive but oncologically adequate procedures that are more technically demanding than the traditional mastectomy procedures.

5.1. Skin-Sparing Mastectomy. Mastectomy with skin preservation was first applied by Freeman to two patients with benign breast disease [37]. Toth and Lappert [38] were the first to report a skin-preserving mastectomy for breast cancer that required considerable preoperative planning of the incisions in order to maximize skin preservation, and thereby facilitate breast reconstruction-whose aesthetic outcome depends considerably on the quantity of breast skin remaining. Their operation consisted of breast gland removal, removal of the nipple-areola complex, biopsy scar, and skin overlying the cancer (if superficial) with preservation of remaining skin and inframammary fold.

The benefits of skin-sparing mastectomy are that it reduces postmastectomy deformity, allows better breast shape after reconstruction, minimizes residual scarring, and reduces the area of skin necessary on myocutaneous flaps. It also reduces the need for contralateral breast surgery to achieve symmetry [39].

Doubts remain about oncological safety of skin-sparing mastectomy, particularly since randomized controlled studies have not been conducted, and residual breast tissue often remains in the skin envelope [40-42]. However, even in cases undergoing conventional mastectomy, residual breast tissue is present on the skin flaps (excluding nippleareola complex) in around 23\% of cases [43]. Furthermore, retrospective studies with followup ranging from 35 to 70 months suggest no differences in recurrence or survival rates between patients undergoing skin-sparing mastectomy with reconstruction and those undergoing conventional mastectomy [44-51].

The most common complications of skin-sparing mastectomy are skin necrosis, infection, and hematoma [52-58]. Infection and hematoma occurs in $2 \%-19 \%$ of cases [52-57]. Skin flap necrosis occurs in about $11 \%$ of cases when there are no risk factors [52]. Similar rates of necrosis are observed after modified radical mastectomy [52]. Smoking is a major risk factor for necrosis [52]. Other factors that increase the risk of necrosis are previous breast irradiation, diabetes, and high body mass index [52]. These complications do not usually delay the administration of adjuvant therapies [59-61]. Reduced skin sensitivity occurs in around 65\% of patients [62].

Indications for skin-sparing mastectomy are BRCA1/2 mutation, intraepithelial neoplasia (DIN or LIN), particularly when the lesion is extensive, multicentric or recurrent, and early-stage breast cancer for which breast-conserving therapy is not suitable [63]. Some of studies support the use of skin-sparing mastectomy following neoadjuvant treatment, for recurrence after breast-conserving surgery, and malignancy after additive mammoplasty [64-66].

Skin involvement by the tumour is an absolute contraindication for skin-sparing mastectomy. Relative contraindications are adjuvant radiotherapy, smoking, previous 
irradiation, high body mass index, and delayed reconstruction $[52,67-71]$.

5.2. Nipple-Sparing Mastectomy. Nipple-sparing mastectomy is a refinement of skin-sparing mastectomy in which the nipple-areolar complex is spared. Once again, its aim is to improve the aesthetic outcome of the reconstruction, which is usually performed immediately [72]. Nipple sparing mastectomy can be associated with intraoperative radiotherapy to the nipple-areolar complex $[72,73]$. One intraoperative irradiation technique (ELIOT) employs electrons at a dose of 16 Gy directly to the nipple-areolar complex. A combined aluminium and lead disc is placed under the complex and over the chest to protect the chest wall [73].

Contraindications for nipple-sparing mastectomy are central quadrant tumours, clinical evidence of nipple-areolar complex involvement, bloody nipple discharge, palpable tumours less than $1 \mathrm{~cm}$ from the nipple, and microcalcifications or other radiological alterations near the nipple [74]. Frozen retroareolar tissue is examined intraoperatively and if positive for malignancy nipple sparing is not performed [72-74].

Petit et al. [73] reported on 289 patients who underwent nipple-sparing mastectomy with intraoperative radiotherapy (ELIOT) to the nipple-areolar complex. Three percent of their patients had total necrosis of the nipple-areolar complex, an additional 9.5\% had partial necrosis, and the entire complex had to be removed in $4.6 \%$. After 1 year of followup, cosmetic outcomes were rated good by $82.3 \%$ of patients and by $84.8 \%$ of surgeons. Radio dystrophy occurred in $7.5 \%$. Nipple-areolar complex sensitivity returned partially in $48 \%$. No local recurrence occurred beneath the preserved nippleareolar complex although followup was short [73].

As with skin-sparing mastectomy, there is concern that retaining the nipple-areolar complex increases the likelihood of disease recurrence; however, the available experience suggests that this is not the case [72-76]. To achieve optimal cosmetic results with oncologic safety, nipple-sparing mastectomy should be performed on only carefully selected patients $[74,75]$.

\subsection{Prophylactic Risk-Reduction Mastectomy. Five-to-ten} percent of breast cancers occur in women with a deleterious mutation in BRCA1, BRCA2, or other breast cancerassociated genes [77, 78]. BRCA1 and BRCA2 mutations are quite penetrating: the cumulative risk of breast cancer is about $65 \%$ in BRCA1-mutation carriers (by age 70) and about $45 \%$ in BRCA2-mutation carriers [79, 80]. Mastectomy has long been proposed as a means of avoiding breast cancer in women with BRCA1 and BRCA2 mutations. Meijers-Heilboer et al. studied the oncological results of riskreduction mastectomy in 139 persons with these mutations, randomizing them to breast cancer screening or reducing risk mastectomy [81]. After an average followup of 3.0 years, breast cancers occurred in 8 screening group women but in none of the mastectomy group [81]. However, mastectomy does not completely eliminate the risk of breast cancer [8284]. Deleterious mutation carriers considering prophylactic mastectomy should be evaluated by a multidisciplinary team consisting of geneticist, oncologist, breast surgeon, plastic surgeon, and psychologist $[85,86]$.

\section{Reconstructive Surgery after Mastectomy}

Options for breast reconstruction after mastectomy consist of autologous transplants, implants, and combinations of both. Autologous breast reconstruction employs both pedicle-based and free flaps. Local pedicle flaps are latissimus dorsi flaps and transverse rectus abdominis myocutaneous (TRAM) flaps. Free flaps include the deep inferior epigastric perforator (DIEP), free TRAM flaps, and gluteal artery perforator (GAP) flaps.

The latissimus dorsi flap was introduced by Schneiders in 1977 and produces satisfactory aesthetic results [87]. Endoscopy can be used to mobilize latissimus dorsi flaps and minimize dorsal scarring. This flap can also be used in association with implants to improve cosmetic results [39].

The DIEP flap, originally proposed by Holmstrom in 1979, makes large-volume transfer possible, with preservation of the abdominal muscles and aponeurotic layers, [88] and reduces complications such as muscular weakness, bulging and hernia; however, the operating time is longer than for other breast reconstructions.

The TRAM flap was introduced by Hartrampf et al. in 1982 [89]. Patients report high levels of aesthetic satisfaction with this technique [90]. However, donor site complications occur more frequently than with DIEP flap. The free superior gluteal artery perforator (S-GAP) flap was first used for breast reconstruction in 1995 [91]. It allows transfer of skin and fat without sacrificing the gluteus maximus.

Several types of expanders and prostheses are used for breast reconstruction. The introduction of anatomically profiled implants improved this type of reconstruction so that good breast volume, shape, and symmetry are routinely achieved with low complication rates [39, 92, 93].

The choice of breast reconstruction technique depends on the anatomical characteristics of the patient and the skill and experience of the plastic surgeon. The risk of reconstruction failure is higher in smokers, obese patients and, those with large breast $[39,52,71]$.

\section{Conclusions}

Mastectomy has evolved from the frankly mutilating but often effective Halsted radical mastectomy to the technically more demanding skin-sparing and nipple-sparing approaches that are increasingly used today. These new mastectomies provide results that are oncologically equivalent to the older operations but make it easier to perform immediate breast reconstructions that achieve good aesthetic results and reduce psychological morbidity. At the same time, mastectomy has been supplanted by surgical approaches that conserve the breast for a large fraction of breast cancer patients in Western countries, in part because breast cancer is diagnosed at a much earlier stage. There is no sign yet that surgery for breast cancer will be supplanted by noninvasive 
treatments, so the way forward seems to be the development of increasingly sophisticated and demanding surgical procedures that are ever more precisely tailored to the individual patient and typically require the skills of a plastic surgeon as well as the breast surgeon and multidisciplinary team. It seems important to develop ways of reducing the failure and complication rates for the breast reconstruction procedures facilitated by the new mastectomies.

\section{Acknowledgment}

The authors thank Don Ward for help with English and Maria Grazia Villardita for editorial assistance.

\section{References}

[1] B. Fisher, J. H. Jeong, S. Anderson, J. Bryant, E. R. Fisher, and N. Wolmark, "Twenty-five-year follow-up of a randomized trial comparing radical mastectomy, total mastectomy, and total mastectomy followed by irradiation," The New England Journal of Medicine, vol. 347, no. 8, pp. 567-575, 2002.

[2] W. S. Halsted, "The results of operations for the cure of cancer of the breast performed at the Johns Hopkins Hospital from June 1889 to January 1894," Annals of Surgery, vol. 20, no. 5, pp. 497-555, 1894.

[3] W. Meyer, "An improved method of the radical operation for carcinoma of the breast," New York Medical Record, vol. 46, pp. 746-749, 1894.

[4] W. S. Halsted, "Developments in skin grafting operation for cancer of the breast," Journal of the American Medical Association, vol. 60, p. 416, 1913.

[5] V. H. Riddielt, "The technique of radical mastectomy: with special reference to the management of the skin short case and the prevention of functional disability," British Journal of Surgery, vol. 36, p. 8, 1948.

[6] C. G. Neumann and H. Conway, "Evaluation of skin grafting in the technique of radical mastectomy in relation to function of the arm," Surgery, vol. 23, no. 3, pp. 584-590, 1948.

[7] M. Bard, "The sequence of emotional reactions in radical mastectomy patients," Public Health Reports, vol. 67, no. 11, pp. 1144-1148, 1952.

[8] J. M. Parker, P. E. Usso, and D. L. Oesterreicher, "Investigation of cause of lymphedema of the upper extremity after radical mastectomy," Radiology, vol. 59, no. 4, pp. 538-545, 1952.

[9] J. R. Von Ronnen, "Spontaneous rib fractures after radical mastectomy," Journal Belge de Radiologie, vol. 38, no. 4, pp. 525-534, 1955.

[10] W. T. Fitts Jr., J. G. Keuhnelian, I. S. Ravdin, and S. Schor, "Swelling of the arm after radical mastectomy. A clinical study of its causes," Surgery, vol. 35, no. 3, pp. 460-464, 1954.

[11] C. D. Haagensen and A. P. Stout, "Carcinoma of the breast: II. Criteria of operability," Annals of Surgery, vol. 118, no. 5, pp. 859-870, 1943.

[12] K. W. Stenstrom and O. J. Baggenstoss, "Results of surgery and radiation for carcinoma of the breast with axillary metastases," Acta Radiologica, vol. 28, pp. 623-632, 1947.

[13] G. H. Fletcher, E. D. Montague, and E. C. White, "Evaluation of irradiation of the peripheral lymphatics in conjunction with radical mastectomy for cancer of the breast," Cancer, vol. 21, no. 5, pp. 791-797, 1968.

[14] J. A. Urban, "Radical mastectomy with en bloc in continuity resection of the internal mammary lymph node chain," The
American Journal of Roentgenology, Radium Therapy, and Nuclear Medicine, vol. 77, no. 3, pp. 431-437, 1957.

[15] J. M. Carey and J. W. Kirklin, "Extended radical mastectomy: a review of its concepts," Proceedings of the Staff Meetings. Mayo Clinic, vol. 27, no. 22, pp. 436-440, 1952.

[16] R. S. Handley and A. C. Thackray, "Invasion of internal mammary lymph nodes in carcinoma of breast," British Medical Journal, vol. 1, pp. 61-63, 1954.

[17] M. Andbeassen, E. Dahl-Iversen, and B. O. Sorensen, "Glandular metastases in carcinoma of the breast. Results of a more radical operation," The Lancet, vol. 263, no. 6804, pp. 176-178, 1954.

[18] M. Margottini, "Recent developments in the surgical treatment of breast carcinoma," Acta Unio Internationalis Contra Cancrum, vol. 8, no. 1, pp. 176-178, 1952.

[19] P. Bucalossi, U. Veronesi, L. Zingo, and C. Cantù, "Enlarged mastectomy for breast cancer: review of 1,213 cases," The American Journal of Roentgenology, Radium Therapy, and Nuclear Medicine, vol. 111, no. 1, pp. 119-122, 1971.

[20] O. H. Wangesteen, "Remarks on extension of the Halsted operation for cancer of the breast," Annals of Surgery, vol. 130, p. 315, 1949.

[21] J. A. Urban, "Extended radical mastectomy for breast cancer," The American Journal of Surgery, vol. 106, no. 3, pp. 399-404, 1963.

[22] E. D. Sugarbaker, "Extended radical mastectomy: its superiority in the treatment of breast cancer," The Journal of the American Medical Association, vol. 187, pp. 96-99, 1964.

[23] J. H. Gray, "Studies of the regeneration of lymphatic vessels," Journal of Anatomy, vol. 74, part 3, pp. 309-335, 1940.

[24] D. H. Patey and W. H. Dyson, "The prognosis of carcinoma of the breast in relation to the type of the mastectomy performed," British Journal of Cancer, vol. 2, pp. 7-13, 1948.

[25] J. L. Madden, S. Kandalaft, and R. A. Bourque, "Modified radical mastectomy," Annals of Surgery, vol. 175, no. 5, pp. 624-634, 1972.

[26] H. Auchincloss, "Modified radical mastectomy: why not?" The American Journal of Surgery, vol. 119, no. 5, pp. 506-509, 1970.

[27] J. W. Berg, "The significance of axillary node levels in the study of breast carcinoma," Cancer, vol. 8, pp. 776-778, 1995.

[28] G. Crile Jr., "Results of simplified treatment of breast cancer," Surgery, Gynecology \& Obstetrics, vol. 118, pp. 517-523, 1964.

[29] C. S. Kennedy and E. Miller, "Simple mastectomy for mammary carcinoma," Annals of Surgery, vol. 157, pp. 161-162, 1963.

[30] S. Kaae and H. Johansen, "Simple mastectomy plus postoperative irradiation by the method of McWhirter for mammary carcinoma," Annals of Surgery, vol. 170, no. 6, pp. 895-899, 1969.

[31] B. Fisher, "Biological and clinical considerations regarding the use of surgery and chemotherapy in the treatment of primary breast cancer," Cancer, vol. 40, supplement 1, pp. 574-587, 1977.

[32] U. Veronesi, R. Saccozzi, M. Del Vecchio et al., "Comparing radical mastectomy with quadrantectomy, axillary dissection, and radiotherapy in patients with small cancers of the breast," The New England Journal of Medicine, vol. 305, no. 1, pp. 6-11, 1981.

[33] B. Fisher, M. Bauer, R. Margolese et al., "Five-year results of a randomized clinical trial comparing total mastectomy and segmental mastectomy with or without radiation in the treatment of breast cancer," The New England Journal of Medicine, vol. 312, no. 11, pp. 665-673, 1985. 
[34] U. Veronesi, N. Cascinelli, L. Mariani et al., "Twentyyear follow-up of a randomized study comparing breastconserving surgery with radical mastectomy for early breast cancer," The New England Journal of Medicine, vol. 347, no. 16, pp. 1227-1232, 2002.

[35] "Consensus statement: treatment of early-stage breast cancer. National Institutes of Health Consensus Development Panel," Journal of the National Cancer Institute. Monographs, vol. 11, pp. 1-5, 1992.

[36] B. Fisher, S. Anderson, J. Bryant et al., “Twenty-year follow-up of a randomized trial comparing total mastectomy, lumpectomy, and lumpectomy plus irradiation for the treatment of invasive breast cancer," The New England Journal of Medicine, vol. 347, no. 16, pp. 1233-1241, 2002.

[37] B. S. Freeman, "Subcutaneous mastectomy for benign breast lesions with immediate or delayed prosthetic replacement," Plastic and Reconstructive Surgery, vol. 30, pp. 676-682, 1962.

[38] B. A. Toth and P. Lappert, "Modified skin incisions for mastectomy: the need for plastic surgical input in preoperative planning," Plastic and Reconstructive Surgery, vol. 87, no. 6, pp. 1048-1053, 1991.

[39] N. Patani and K. Mokbel, "Oncological and aesthetic considerations of skin-sparing mastectomy," Breast Cancer Research and Treatment, vol. 111, no. 3, pp. 391-403, 2008.

[40] F. E. Barton, J. M. English, W. B. Kingsley, and M. Fietz, "Glandular excision in total glandular mastectomy and modified radical mastectomy: a comparison," Plastic and Reconstructive Surgery, vol. 88, no. 3, pp. 389-394, 1991.

[41] R. Z. Torresan, C. C. Dos Santos, H. Brenelli, H. Okamura, and M. Alvarenga, "Residual glandular tissue after skin-sparing mastectomies," Breast Journal, vol. 11, no. 5, pp. 374-375, 2005.

[42] R. Z. Torresan, C. C. D. Santos, H. Okamura, and M. Alvarenga, "Evaluation of residual glandular tissue after skinsparing mastectomies," Annals of Surgical Oncology, vol. 12, no. 12, pp. 1037-1044, 2005.

[43] C. M. Ho, C. K. L. Mak, Y. Lau, W. Y. Cheung, M. C. M. Chan, and W. K. Hung, "Skin involvement in invasive breast carcinoma: safety of skin-sparing mastectomy," Annals of Surgical Oncology, vol. 10, no. 2, pp. 102-107, 2003.

[44] L. A. Newman, H. M. Kuerer, K. K. Hunt et al., "Presentation, treatment, and outcome of local recurrence after skin- sparing mastectomy and immediate breast reconstruction," Annals of Surgical Oncology, vol. 5, no. 7, pp. 620-626, 1998.

[45] R. M. Simmons, S. K. Fish, L. Gayle et al., "Local and distant recurrence rates in skin-sparing mastectomies compared with non-skin-sparing mastectomies," Annals of Surgical Oncology, vol. 6, no. 7, pp. 676-681, 1999.

[46] D. E. Rivadeneira, R. M. Simmons, S. K. Fish et al., "Skinsparing mastectomy with immediate breast reconstruction: a critical analysis of local recurrence," Cancer Journal, vol. 6, no. 5, pp. 331-335, 2000.

[47] R. M. Greenway, L. Schlossberg, and W. C. Dooley, "Fifteenyear series of skin-sparing mastectomy for stage 0 to 2 breast cancer," American Journal of Surgery, vol. 190, no. 6, pp. 918 922, 2005.

[48] T. J. Meretoja, S. Rasia, K. A. J. Von Smitten, S. L. AskoSeljavaara, H. O. M. Kuokkanen, and T. A. Jahkola, "Late results of skin-sparing mastectomy followed by immediate breast reconstruction," British Journal of Surgery, vol. 94, no. 10, pp. 1220-1225, 2007.

[49] T. J. Meretoja, K. A. J. von Smitten, M. H. K. Leidenius, C. Svarvar, P. S. Heikkilä, and T. A. Jahkola, "Local recurrence of stage 1 and 2 breast cancer after skin-sparing mastectomy and immediate breast reconstruction in a 15-year series," European Journal of Surgical Oncology, vol. 33, no. 10, pp. 1142-1145, 2007.

[50] G. W. Carlson, T. M. Styblo, R. H. Lyles et al., "The use of skin sparing mastectomy in the treatment of breast cancer: the Emory experience," Surgical Oncology, vol. 12, no. 4, pp. 265269, 2003.

[51] G. H. Cunnick and K. Mokbel, "Skin-sparing mastectomy," American Journal of Surgery, vol. 188, no. 1, pp. 78-84, 2004.

[52] G. W. Carlson, J. Bostwick, T. M. Styblo et al., "Skin-sparing mastectomy: oncologic and reconstructive considerations," Annals of Surgery, vol. 225, no. 5, pp. 570-578, 1997.

[53] W. J. Sotheran and R. M. Rainsbury, "Skin-sparing mastectomy in the UK: a review of current practice," Annals of the Royal College of Surgeons of England, vol. 86, no. 2, pp. 82-86, 2004.

[54] S. A. Slavin, S. J. Schnitt, R. B. Duda et al., "Skin-sparing mastectomy and immediate reconstruction: oncologic risks and aesthetic results in patients with early-stage breast cancer," Plastic and Reconstructive Surgery, vol. 102, no. 1, pp. 49-62, 1998.

[55] T. J. Eberlein, L. D. Crespo, B. L. Smith, C. A. Hergrueter, L. Douville, and E. Eriksson, "Prospective evaluation of immediate reconstruction after mastectomy," Annals of Surgery, vol. 218, no. 1, pp. 29-36, 1993.

[56] K. Sandelin, A. M. Billgren, and M. Wickman, "Management, morbidity, and oncologic aspects in 100 consecutive patients with immediate breast reconstruction," Annals of Surgical Oncology, vol. 5, no. 2, pp. 159-165, 1998.

[57] W. O'Brien, P. O. Hasselgren, R. P. Hummel et al., "Comparison of postoperative wound complications and early cancer recurrence between patients undergoing mastectomy with or without immediate breast reconstruction," American Journal of Surgery, vol. 166, no. 1, pp. 1-5, 1993.

[58] R. M. Rainsbury, "Skin-sparing mastectomy," British Journal of Surgery, vol. 93, no. 3, pp. 276-281, 2006.

[59] P. C. Furey, D. C. Macgillivray, C. L. Castiglione, and L. Allen, "Wound complications in patients receiving adjuvant chemotherapy after mastectomy and immediate breast reconstruction for breast cancer," Journal of Surgical Oncology, vol. 55, no. 3, pp. 194-197, 1994.

[60] G. L. Yule, M. J. Concannon, G. Croll, and C. L. Puckett, "Is there liability with chemotherapy following immediate breast construction?" Plastic and Reconstructive Surgery, vol. 97, no. 5, pp. 969-973, 1996.

[61] T. M. Allweis, M. E. Boisvert, S. E. Otero, D. J. Perry, N. H. Dubin, and D. A. Priebat, "Immediate reconstruction after mastectomy for breast cancer does not prolong the time to starting adjuvant chemotherapy," American Journal of Surgery, vol. 183, no. 3, pp. 218-221, 2002.

[62] R. K. Gendy, J. A. Able, and R. M. Rainsbury, "Impact of skin-sparing mastectomy with immediate reconstruction and breast-sparing reconstruction with miniflaps on the outcomes of oncoplastic breast surgery," British Journal of Surgery, vol. 90, no. 4, pp. 433-439, 2003.

[63] C. M. Chen, J. J. Disa, V. Sacchini et al., "Nipple-sparing mastectomy and immediate tissue expander/implant breast reconstruction," Plastic and Reconstructive Surgery, vol. 124, no. 6, pp. 1772-1780, 2009.

[64] R. D. Foster, L. J. Esserman, J. P. Anthony, E. S. S. Hwang, and H. Do, "Skin-sparing mastectomy and immediate breast reconstruction: a prospective cohort study for the treatment 
of advanced stages of breast carcinoma," Annals of Surgical Oncology, vol. 9, no. 5, pp. 462-466, 2002.

[65] J. J. Disa, P. G. Cordeiro, A. H. Heerdt, J. A. Petrek, P. J. Borgen, and D. A. Hidalgo, "Skin-sparing mastectomy and immediate autologous tissue reconstruction after wholebreast irradiation," Plastic and Reconstructive Surgery, vol. 111, no. 1, pp. 118-124, 2003.

[66] G. W. Carlson, B. Moore, J. F. Thornton, M. Elliott, and G. Bolitho, "Breast cancer after augmentation mammaplasty: treatment by skin-sparing mastectomy and immediate reconstruction," Plastic and Reconstructive Surgery, vol. 107, no. 3, pp. 687-692, 2001.

[67] S. J. Victor, D. M. Brown, E. M. Horwitz et al., "Treatment outcome with radiation therapy after breast augmentation or reconstruction in patients with primary breast carcinoma," Cancer, vol. 82, no. 7, pp. 1303-1309, 1998.

[68] S. L. Spear and C. Onyewu, "Staged breast reconstruction with saline-filled implants in the irradiated breast: recent trends and therapeutic implications," Plastic and Reconstructive Surgery, vol. 105, no. 3, pp. 930-942, 2000.

[69] R. H. Schuster, R. R. Kuske, V. L. Young, B. Fineberg, R. H. Grobstein, and S. H. Miller, "Breast reconstruction in women treated with radiation therapy for breast cancer: cosmesis, complications, and tumor control," Plastic and Reconstructive Surgery, vol. 90, no. 3, pp. 445-454, 1992.

[70] P. M. Peyser, J. A. Abel, V. F. Straker, V. L. Hall, and R. M. Rainsbury, "Ultra-conservative skin-sparing 'keyhole' mastectomy and immediate breast and areola reconstruction," Annals of the Royal College of Surgeons of England, vol. 82, no. 4, pp. 227-235, 2000.

[71] C. S. Hultman, S. Daiza, and L. T. Furlow, "Skin-sparing mastectomy flap complications after breast reconstruction: review of incidence, management, and outcome," Annals of Plastic Surgery, vol. 50, no. 3, pp. 249-255, 2003.

[72] J. Y. Petit, U. Veronesi, R. Orecchia et al., "Nipple-sparing mastectomy in association with intra operative radiotherapy (ELIOT): a new type of mastectomy for breast cancer treatment," Breast Cancer Research and Treatment, vol. 96, no. 1, pp. 47-51, 2006.

[73] J. Y. Petit, U. Veronesi, A. Luini et al., "When mastectomy becomes inevitable: the nipple-sparing approach," Breast, vol. 14, no. 6, pp. 527-531, 2005.

[74] J. E. Rusby, B. L. Smith, and G. P. H. Gui, "Nipple-sparing mastectomy," British Journal of Surgery, vol. 97, no. 3, pp. 305$316,2010$.

[75] A. P. Chung and V. Sacchini, "Nipple-sparing mastectomy: where are we now?" Surgical Oncology, vol. 17, no. 4, pp. 261266, 2008.

[76] K. P. Benediktsson and L. Perbeck, "Survival in breast cancer after nipple-sparing subcutaneous mastectomy and immediate reconstruction with implants: a prospective trial with 13 years median follow-up in 216 patients," European Journal of Surgical Oncology, vol. 34, no. 2, pp. 143-148, 2008.

[77] E. B. Claus, J. M. Schildkraut, W. D. Thompson, and N. J. Risch, "The genetic attributable risk of breast and ovarian cancer," Cancer, vol. 77, no. 11, pp. 2318-2324, 1996.

[78] R. Fu, E. L. Harris, M. Helfand, and H. D. Nelson, "Estimating risk of breast cancer in carriers of BRCA1 and BRCA2 mutations: a meta-analytic approach," Statistics in Medicine, vol. 26, no. 8, pp. 1775-1787, 2007.

[79] A. Antoniou, P. D. P. Pharoah, S. Narod et al., "Average risks of breast and ovarian cancer associated with BRCA1 or BRCA2 mutations detected in case series unselected for family history: a combined analysis of 22 studies," American Journal of Human Genetics, vol. 72, no. 5, pp. 1117-1130, 2003.

[80] S. Chen and G. Parmigiani, "Meta-analysis of BRCA1 and BRCA2 penetrance," Journal of Clinical Oncology, vol. 25, no. 11, pp. 1329-1333, 2007.

[81] H. Meijers-Heijboer, B. Van Geel, W. L. J. Van Putten et al., "Breast cancer after prophylactic bilateral mastectomy in women with a BRCA1 or BRCA2 mutation," The New England Journal of Medicine, vol. 345, no. 3, pp. 159-164, 2001.

[82] L. Lostumbo, N. Carbine, and J. Wallace, "Prophylactic mastectomy for the prevention of breast cancer," Cochrane Database of Systematic Reviews, vol. 11, Article ID CD002748, 2010.

[83] L. Lostumbo, N. Carbine, J. Wallace, and J. Ezzo, "Prophylactic mastectomy for the prevention of breast cancer," Cochrane Database of Systematic Reviews, no. 4, Article ID CD002748, 2004.

[84] H. M. Kuerer, E. S. Hwang, and L. J. Esserman, "Prophylactic mastectomy in women with a high risk of breast cancer," The New England Journal of Medicine, vol. 340, no. 23, pp. 1837 1839, 1999.

[85] M. B. Hatcher, L. Fallowfield, and R. A'Hern, “The psychosocial impact of bilateral prophylacttc mastectomy: prospective study using questionnaires and semistructured interviews," British Medical Journal, vol. 322, no. 7278, pp. 76-79, 2001.

[86] P. J.C. Bresser, C. Seynaeve, A. R. Van Gool et al., "Satisfaction with prophylactic mastectomy and breast reconstruction in genetically predisposed women," Plastic and Reconstructive Surgery, vol. 117, no. 6, pp. 1675-1682, 2006.

[87] W. J. Schneider, H. L. Hill Jr., and R. G. Brown, "Latissimus dorsi myocutaneous flap for breast reconstruction," British Journal of Plastic Surgery, vol. 30, no. 4, pp. 277-281, 1977.

[88] H. Holmstrom, "The free abdominoplasty flap and its use in breast reconstruction. An experimental study and clinical case report," Scandinavian Journal of Plastic and Reconstructive Surgery, vol. 13, no. 3, pp. 423-427, 1979.

[89] C. R. Hartrampf, M. Scheflan, and P. W. Black, "Breast reconstruction with a transverse abdominal island flap," Plastic and Reconstructive Surgery, vol. 69, no. 2, pp. 216-225, 1982.

[90] J. H. Yueh, S. A. Slavin, T. Adesiyun et al., "Patient satisfaction in postmastectomy breast reconstruction: a comparative evaluation of DIEP, TRAM, latissimus flap, and implant techniques," Plastic and Reconstructive Surgery, vol. 125, no. 6, pp. 1585-1595, 2010.

[91] R. J. Allen and C. Tucker Jr., "Superior gluteal artery perforator free flap for breast reconstruction," Plastic and Reconstructive Surgery, vol. 95, no. 7, pp. 1207-1212, 1995.

[92] J. F. Delgado, R. F. García-Guilarte, M. R. Palazuelo, J. I. S. Mendez, and C. C. Pérez, "Immediate breast reconstruction with direct, anatomic, gel-cohesive, extra-projection prosthesis: 400 cases," Plastic and Reconstructive Surgery, vol. 125, no. 6, pp. 1599-1605, 2010.

[93] G. P. H. Gui, S. M. Tan, E. C. Faliakou, C. Choy, R. A'Hern, and A. Ward, "Immediate breast reconstruction using biodimensional anatomical permanent expander implants: a prospective analysis of outcome and patient satisfaction," Plastic and Reconstructive Surgery, vol. 111, no. 1, pp. 125-138, 2003. 


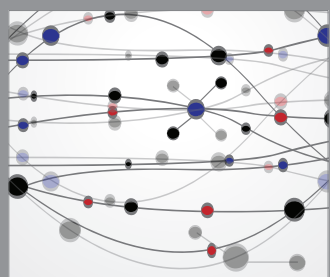

The Scientific World Journal
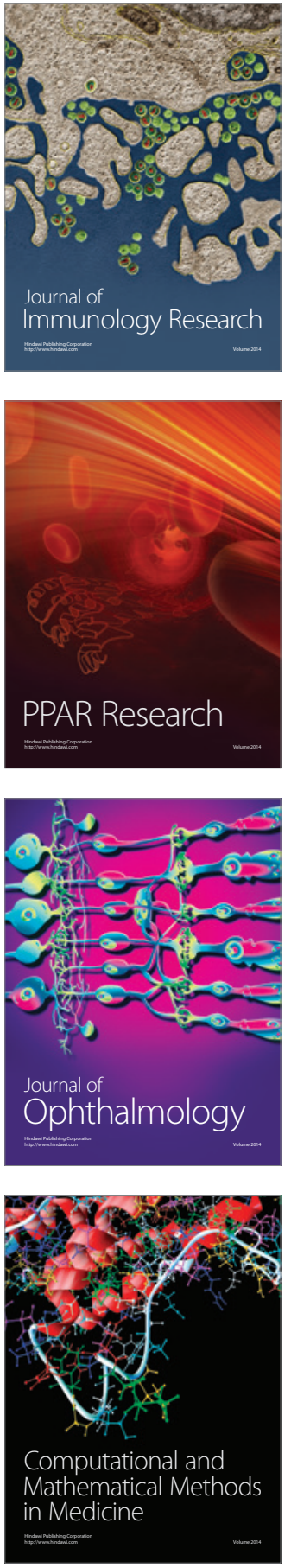

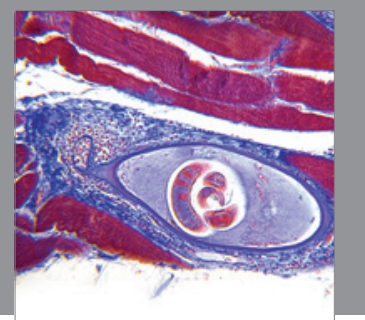

Gastroenterology

Research and Practice
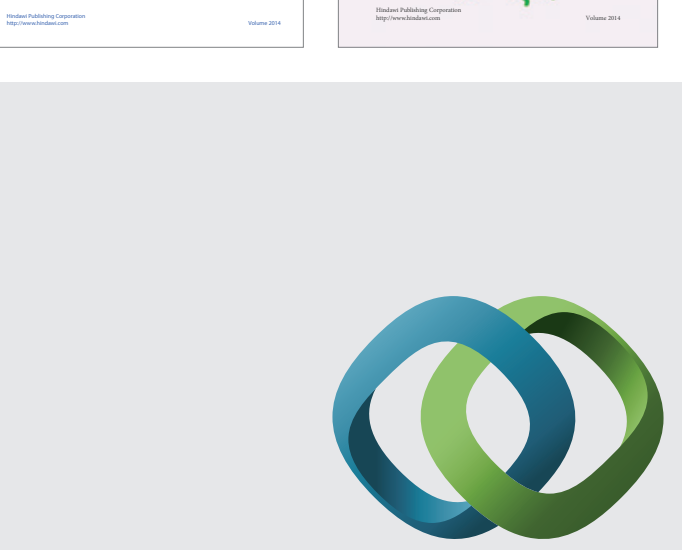

\section{Hindawi}

Submit your manuscripts at

http://www.hindawi.com
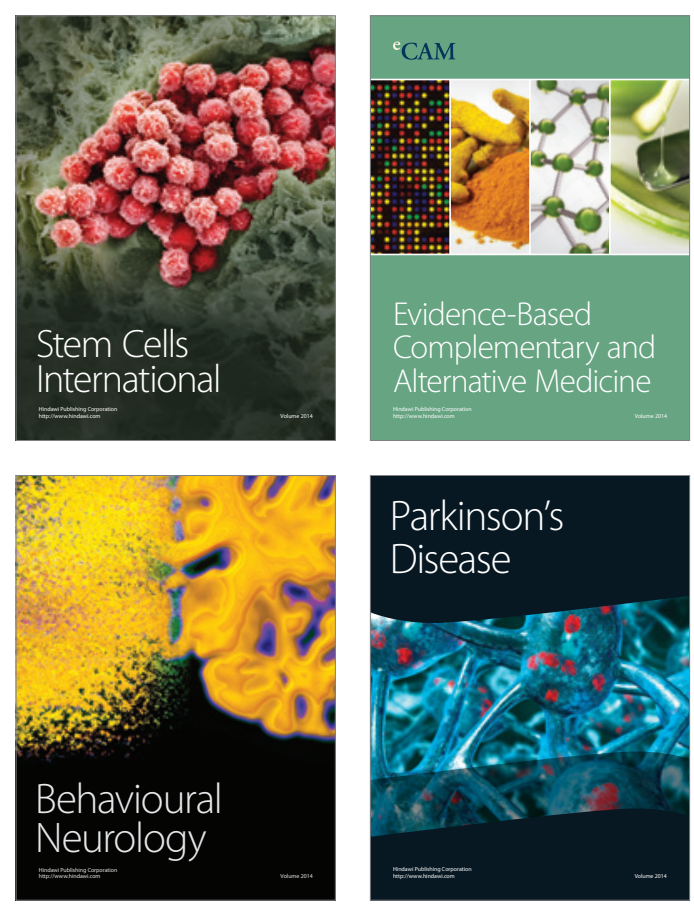

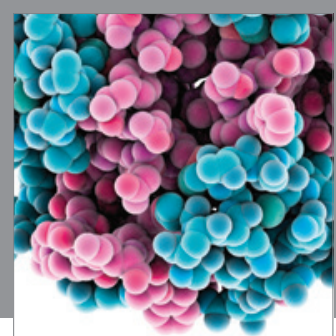

Journal of
Diabetes Research

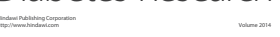

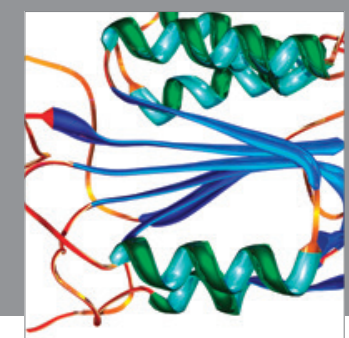

Disease Markers
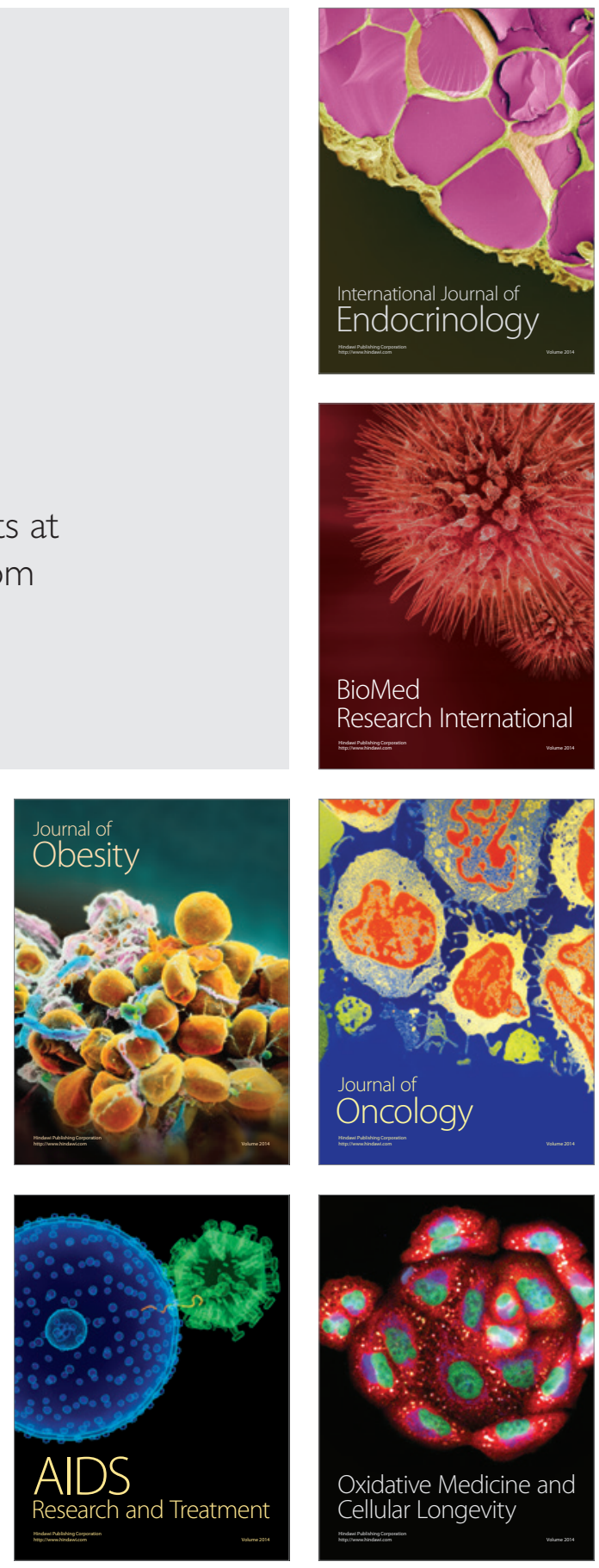